\title{
Improvement of Cobalt Dispersion on Co/SBA-15 and Co/SBA-16 Catalysts by Ultrasound and Vacuum Treatments during Post-Impregnation Step
}

\author{
Jittraporn Kruatim $^{1}$, Sasiradee Jantasee ${ }^{2}$, and Bunjerd Jongsomjit ${ }^{1}$ ** \\ 1 Center of Excellence on Catalysis and Catalytic Reaction Engineering, Department of Chemical \\ Engineering, Faculty of Engineering, Chulalongkorn University, Bangkok 10330, Thailand \\ 2 Department of Chemical Engineering, Faculty of Engineering, Rajamangala University of Technology \\ Thanyaburi, Pathum Thani 12110, Thailand \\ *E-mail: bunjerd.j@chula.ac.th (Correspondingauthor)
}

\begin{abstract}
The Co/SBA-15 and the Co/SBA-16 catalysts having $20 \mathrm{wt} \%$ of cobalt were prepared by the conventional impregnation method. Then, the post-impregnation treatments including vacuum and ultrasound treatments were applied. The synthesized catalysts were characterized by means of $\mathrm{N}_{2}$ physisorption, small angle $\mathrm{X}$-ray diffraction (SAXRD), wide angle X-ray diffraction (XRD), scanning electron microscopy and energy dispersive X-ray spectroscopy (SEM/EDX), transmission electron microscopy (TEM), and temperature-programmed reduction (TPR). The results show that the synthesized SBA-15 had hexagonal structure and the synthesized SBA-16 had the cubic structure. The vacuum and the ultrasound treatments after incipient wetness impregnation can apparently enhance the dispersion of cobalt on the SBA- 15 catalysts due to the decrease of the metal crystallite size. However, only the vacuum treatment was suitable for the Co/SBA-16. After reduction, no cobalt-silicate compound was detected based on XRD measurement. Both postimpregnation treatments can also decrease the metal-support interaction resulting in increased activity for $\mathrm{CO}_{2}$ hydrogenation under methanation.
\end{abstract}

Keywords: Cobalt catalyst, mesoporous materials, metal-support interaction, hydrogenation.

ENGINEERING JOURNAL Volume 21 Issue 1

Received 21 January 2016

Accepted 19 May 2016

Published 31 January 2017

Online at http://www.engj.org/

DOI:10.4186/ej.2017.21.1.17 


\section{Introduction}

For years, carbon dioxide $\left(\mathrm{CO}_{2}\right)$ has been seriously attended for environmental protection. $\mathrm{CO}_{2}$ hydrogenation process is one of the promising choices to reduce $\mathrm{CO}_{2}$ and to produce hydrocarbon compounds. There are many reports upon $\mathrm{CO}_{2}$ hydrogenation using cobalt catalysts to produce long chain hydrocarbon products [1-3]. Nevertheless, the activity and selectivity do not only depend on the catalyst compositions, but they are also dependent upon the catalyst preparation methods. At present, the incipient wetness impregnation is widely used for preparing the catalyst. However, this impregnation method shows low metal dispersion. Therefore, many researchers have done on making high metal distribution catalysts. Pirola et al. [4] reported the advantages of using the ultrasound treatment after impregnation. They indicated that the ultrasound treatment diminishes the crystallite size resulting in an improvement of the metal cluster distribution on the support. This treatment also enhances the catalytic performance compared to the basic impregnation method. Another way to make high metal dispersion reported by Zhao et al. [5] is the vacuum treatment after impregnation. They studied the effect of different environments on the preparation of the $\mathrm{Co} / \mathrm{SiO}_{2}$ catalysts, which were impregnated under common and vacuum conditions. The catalyst impregnated under the vacuum condition displays a small cluster which states in the pores of supports making vigorous interaction between cobalt and supports. Although the smaller particles show high metal dispersion, the strong interaction causes a decrease in catalytic activity.

Since mesoporous silica was discovered in 1992 [6, 7], various applications have been applied to mesoporous silica such as catalysis [8-12], adsorption and separation [13, 14], optical application [15], etc. Silica is divided into four categories by their diameters, namely microporous silica, mesoporous silica, macroporous silica and megaporous silica [16]. Mesoporous silica has a uniform diameter in the range of 2$50 \mathrm{~nm}$. It was synthesized from block copolymer surfactant with organic silica as silica source under acidic condition. The SBA series are well-known mesoporous silica because of their high thermal and hydrothermal stability [17], high surface area, large pore volume [18], controllable porosity [19], and easy preparation.SBA15 is one of most studies as catalyst support and separation because of its uniform pore size, hexagonal array of one-dimensional cylindrical channels, large surface areas, and high thermal stability [20]. However, the structure of the SBA-15 can be changed by using different solvents, surfactants or salt additions in the preparing step. The use of Pluronic F127 instead of Pluronic P123 as a surfactant provides mesoporous silica with a large cage-like pores formed in a three-dimensional body-centered cubic named as SBA-16[21].

This research focuses on the investigation of characteristics and catalytic properties of mesoporous silicas (SBA-15 and SBA-16)-supported cobalt catalysts. In addition, the ultrasound and vacuum treatments as the post-impregnation step have been conducted for catalyst improvement. Catalysts were characterized using XRD, TEM, SEM/EDX, N2physisorption and TPR. Their catalytic properties were tested in $\mathrm{CO}_{2}$ hydrogenation under methanation.

\section{Experimental}

\subsection{Materials}

Pluronic P123, pluronic F127, tetraethyl orthosilicate (TEOS, 98\%) and Cobalt (II) nitrate hexahydrate ( $\geq 98 \%)$ were purchased from Sigma-Aldrich Co. Lcc. Hydrochloric acid (37\%) was purchased from QREC.

\subsection{Preparation of Supports}

Two types of mesoporous silicas, which are SBA-15 and SBA-16 were synthesized based on the procedure described by Zhao et al. [17] as follows:

\subsubsection{Preparation of SBA-15}

Four grams of pluronic P123 was added into the solution of $120 \mathrm{~g}$ of $2 \mathrm{M} \mathrm{HCl}$ and $30 \mathrm{~g}$ of deionized water. After stirring, a clear solution was obtained. Then, $8.5 \mathrm{~g}$ of TEOS was added into the solution. The mixture was stirred for $20 \mathrm{~h}$ at room temperature followed by aging at $80{ }^{\circ} \mathrm{C}$ for $24 \mathrm{~h}$. The template was removed by washing with deionized water for 5-7 times followed by filtration. Then, the resulting solid were dried at room temperature and calcined in air at $500{ }^{\circ} \mathrm{C}$ for $6 \mathrm{~h}$ to obtain the SBA- 15 . 


\subsubsection{Preparation of SBA-16}

The synthesis procedure of the SBA-16 was similar to that of the SBA-15, but using pluronic F127 as a template. $1.5 \mathrm{~g}$ of pluronic $\mathrm{F} 127$ was added into the solution of $120 \mathrm{~g}$ of $2 \mathrm{M} \mathrm{HCl}$ and $30 \mathrm{~g}$ of deionized water. $8.5 \mathrm{~g}$ of TEOS was added to the clear mixture and stirred for $20 \mathrm{~h}$ at room temperature followed by aging at $105^{\circ} \mathrm{C}$ for $48 \mathrm{~h}$. The resulting solid was obtained by washing with deionized water and filtering. The solid particles were dried at room temperature and calcination at $560^{\circ} \mathrm{C}$ for $4 \mathrm{~h}$ to obtain the SBA-16.

\subsection{Preparation of Catalysts}

The SBA-15 and SBA-16 supported cobalt catalysts were prepared by using cobalt (II) nitrate hexahydrate $\left[\mathrm{Co}\left(\mathrm{NO}_{3}\right)_{2} \cdot 6 \mathrm{H}_{2} \mathrm{O}\right]$ as a precursor. The solution of deionized water and $20 \mathrm{wt} \%$ of cobalt was dropped into the support by incipient wetness impregnation. The catalysts were denoted as the Co/SBA-15-N and the Co/SBA-16-N.

\subsection{Post-Impregnation Treatment of Catalyst}

There were two post-impregnation treatments having details as follows:

(i) Ultrasound treatment was used after the incipient wetness impregnation as mentioned above. The catalysts were sonicated for $30 \mathrm{~min}$ at room temperature. Then, they were dried at $105^{\circ} \mathrm{C}$ for $12 \mathrm{~h}$ and calcined in air at $500{ }^{\circ} \mathrm{C}$ for $6 \mathrm{~h}$. The catalysts were named as the Co/SBA-15-U and the Co/SBA-16-U.

(ii) Vacuum treatment was also performed after the incipient wetness impregnation. The wet catalysts were transferred into filtration flask. Then, a vacuum condition was created in the flask by removing air from the flask using a vacuum pump at room temperature for $30 \mathrm{~min}$. The treated catalysts were dried at $105^{\circ} \mathrm{C}$ for $12 \mathrm{~h}$ and calcined in air at $500{ }^{\circ} \mathrm{C}$ for $6 \mathrm{~h}$. They were named as the Co/SBA-15-V and the Co/SBA-16-V.

\subsection{Catalyst Characterizations}

The $\mathrm{N}_{2}$ physisorption was performed for determining the specific surface area, pore size and pore volume of the supports, using Micromeritics ASAP 2020 equipment at $-196{ }^{\circ} \mathrm{C}$. Before the measurement, bothSBA-15 and the SBA-16 samples were outgases at $200{ }^{\circ} \mathrm{C}$ for $3 \mathrm{~h}$, and then at $250^{\circ} \mathrm{C}$ for another $3 \mathrm{~h}$, consecutively in order to remove all moisture and gases in the pores.

Small angle X-ray diffraction (SAXRD) is used to identify the chemical structure of the support. The Bruker AXS Model D8 Discover X-ray diffractometer having a VÅNTEC-1 detector (Super Speed Detector) connected to computer was used. It was carried out by using $\mathrm{Cu}$ radiation that was scanned at a rate of 0.3 second/step in the $2 \theta$ range of $0.5-6$ degrees resolution of $0.02^{\circ}$.

The SIEMENS D-5000 X-ray diffractometer connected to a computer with Diffract ZT version 3.3 program was used for the XRD measurement of the catalysts. The experiment was carried out by using $\mathrm{Cu}$ $\mathrm{K}_{\alpha}(\alpha=1.54439 \AA)$ radiation with $\mathrm{Ni}$ filter. The spectra were scanned at a rate of 0.02 degree $/ \mathrm{min}$ in the $2 \theta$ of $15-80$ degrees with a resolution of $0.04^{\circ}$.

The morphology of the catalysts was determined by scanning electron microscopy (SEM) and transmission electron microscopy (TEM) using JEOL mode JSM-6400 and JEOL JEM-2101. Energy dispersive X-ray spectroscopy (EDX) measures the elemental distribution in catalysts using Link Isis series 300 program.

Temperature programmed reduction (TPR) measurements were performed on a Micrometritics Pulse Chemisorb 2750 instrument. $0.05 \mathrm{~g}$ of the catalyst was pretreated with helium at $100^{\circ} \mathrm{C}$ for $1 \mathrm{~h}$. After cooling down to room temperature, a flow of $\mathrm{H}_{2} / \mathrm{Ar}(15 \mathrm{ml} / \mathrm{min})$ was passed through the catalyst while the temperature was raised to $800{ }^{\circ} \mathrm{C}$. 


\subsection{Reaction study in $\mathrm{CO}_{2} \mathrm{Hydrogenation}$}

$\mathrm{CO}_{2}$ hydrogenation was performed using fixed-bed microreactor. First, $0.1 \mathrm{~g}$ of catalyst was packed over the quartz wool. The catalyst was pretreated with $\mathrm{H}_{2}$ and the temperature was raised to $350{ }^{\circ} \mathrm{C}$ from room temperature. The catalyst was held at this condition for $3 \mathrm{~h}$. Then, it was cooled down to $220{ }^{\circ} \mathrm{C}$. After that, $\mathrm{H}_{2} / \mathrm{CO}_{2}$ having the ratios of $10 / 1$ was fed into the microreactor to start the reaction. Products were analyzed by Gas Chromatography. The thermal conductivity detector (TCD) was used to detect $\mathrm{CO}$ and $\mathrm{CO}_{2}$, and flame ionization detection (FID) was used to detect $\mathrm{CH}_{4}$ and larger hydrocarbons.

\section{Results and Discussion}

\subsection{Characteristics of Supports and Catalysts}

$\mathrm{N}_{2}$ physisorption was used to determine the specific surface area, pore size and pore volume of the SBA-15 and the SBA-16. The textural properties are summarized in Table 1. Both of mesoporous silicas (Type IV) have large surface areas. The SBA-15 has a surface area of $674 \mathrm{~m}^{2} / \mathrm{g}$, while the SBA-16 has slightly lower surface area of $664 \mathrm{~m}^{2} / \mathrm{g}$. Therefore, the SBA-15 implies little more hydrothermal stable.

Table 1. $\mathrm{N}_{2}$ physisorption results of the SBA-15 and the SBA-16.

\begin{tabular}{cccc}
\hline Support & BET surface area $\left(\mathbf{m}^{2} / \mathbf{g}\right)$ & Pore volume $\left(\mathbf{c m}^{3} / \mathbf{g}\right)$ & Pore size $(\mathbf{n m})$ \\
\hline SBA-15 & 674 & 0.66 & 3.92 \\
SBA-16 & 664 & 0.43 & 2.61 \\
\hline
\end{tabular}

The SAXRD patterns shown in Fig. 1at low diffraction angle were essentially confirmed the mesoporous silica structure of the SBA-15 and the SBA-16. For the SBA-15, the presence of reflection index according to (100), (110) and (200) confirms 2D hexagonal symmetry, which is in agreement with those of Zhao at al. [17]. The diffraction peaks of the SBA-16 could be indexed in the cubic structure as (100), (111) and (200), respectively [22]. The XRD with wide diffraction angles was used to determine the cobalt oxide crystalline $\left(\mathrm{CO}_{3} \mathrm{O}_{4}\right)$ of catalysts after the impregnation and the post-impregnation treatments and the results were shown in Fig. 2. The diffraction peaks at $19^{\circ}, 31.3^{\circ}, 36.9^{\circ}, 44.9^{\circ}, 57^{\circ}, 59.4^{\circ}$ and $65.3^{\circ}$ surely indicate the $\mathrm{Co}_{3} \mathrm{O}_{4}$ over the supports for all impregnation methods [23]. The small peak around $38^{\circ}$ was also appeared and can be attributed to the presence of various $\mathrm{Co}_{\mathrm{x}} \mathrm{O}_{\mathrm{y}}$ species on the support [24].

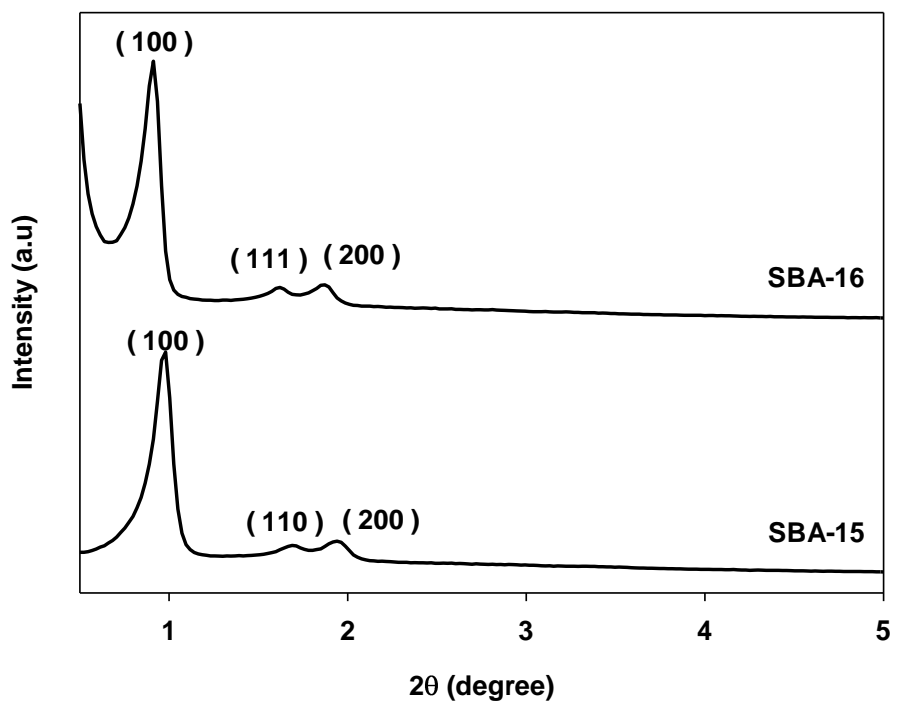

Fig. 1. SAXRD patterns of the SBA-15 and the SBA-16. 

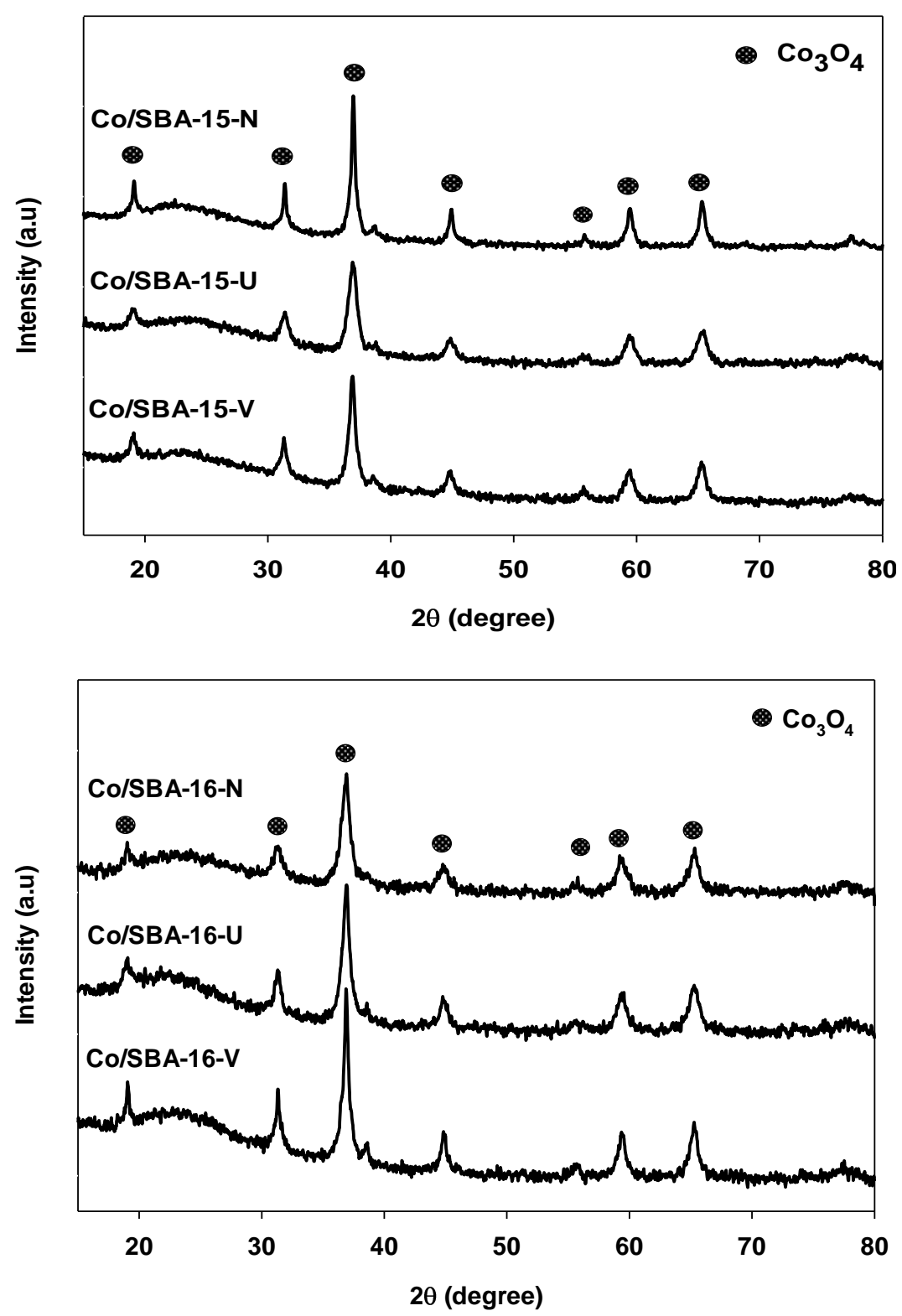

Fig. 2. XRD patterns of the Co/SBA-15 and Co/SBA-16 catalysts.

The TEM images of the supports are presented in Fig. 3. It is an alternative way to identify the structure of the SBA-15 and the SBA-16. The SBA-15 presents a hexagonal structure as a honeycomb. On the other hand, the SBA-16 displays a cubic body as a cage structure connected in worm-like shape. Moreover, the cobalt oxide distributions on the supports are shown in Fig. 4. It is clearly seen that the ultrasound and vacuum treatments after impregnation can increase the cobalt oxide distribution on the supports. This is consistent with previous reports that the post-impregnation treatments using ultrasound and vacuum improved the metal dispersion $[2,4]$. Interestingly, the catalysts treated by the vacuum after impregnation had the cobalt oxide crystallites in the inner pore (well dispersed), while the ultrasound treatment produced the cobalt oxide crystallites at the outer silica surface (agglomeration) as seen from TEM. 


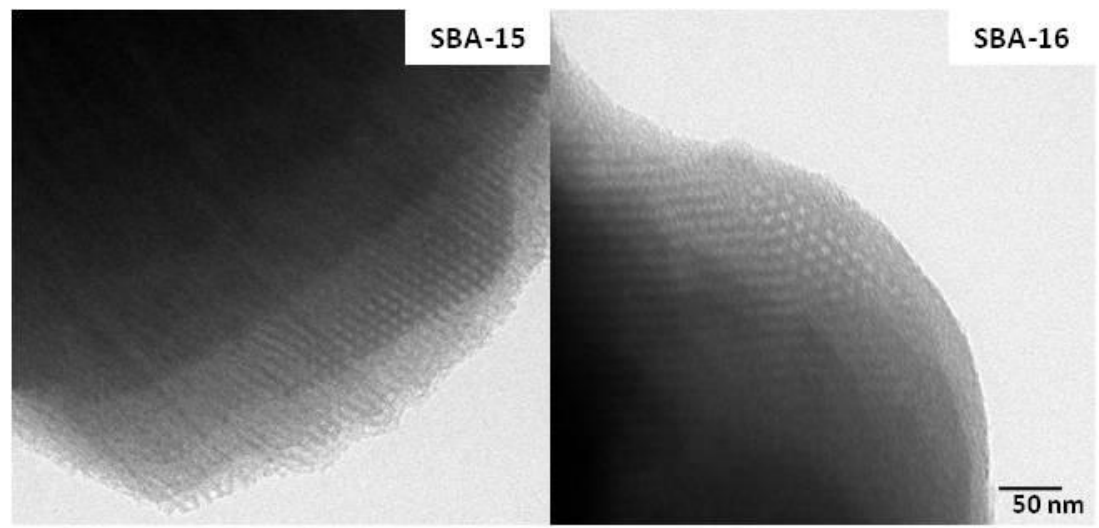

Fig. 3. TEM images of the SBA-15 and SBA-16 supports.

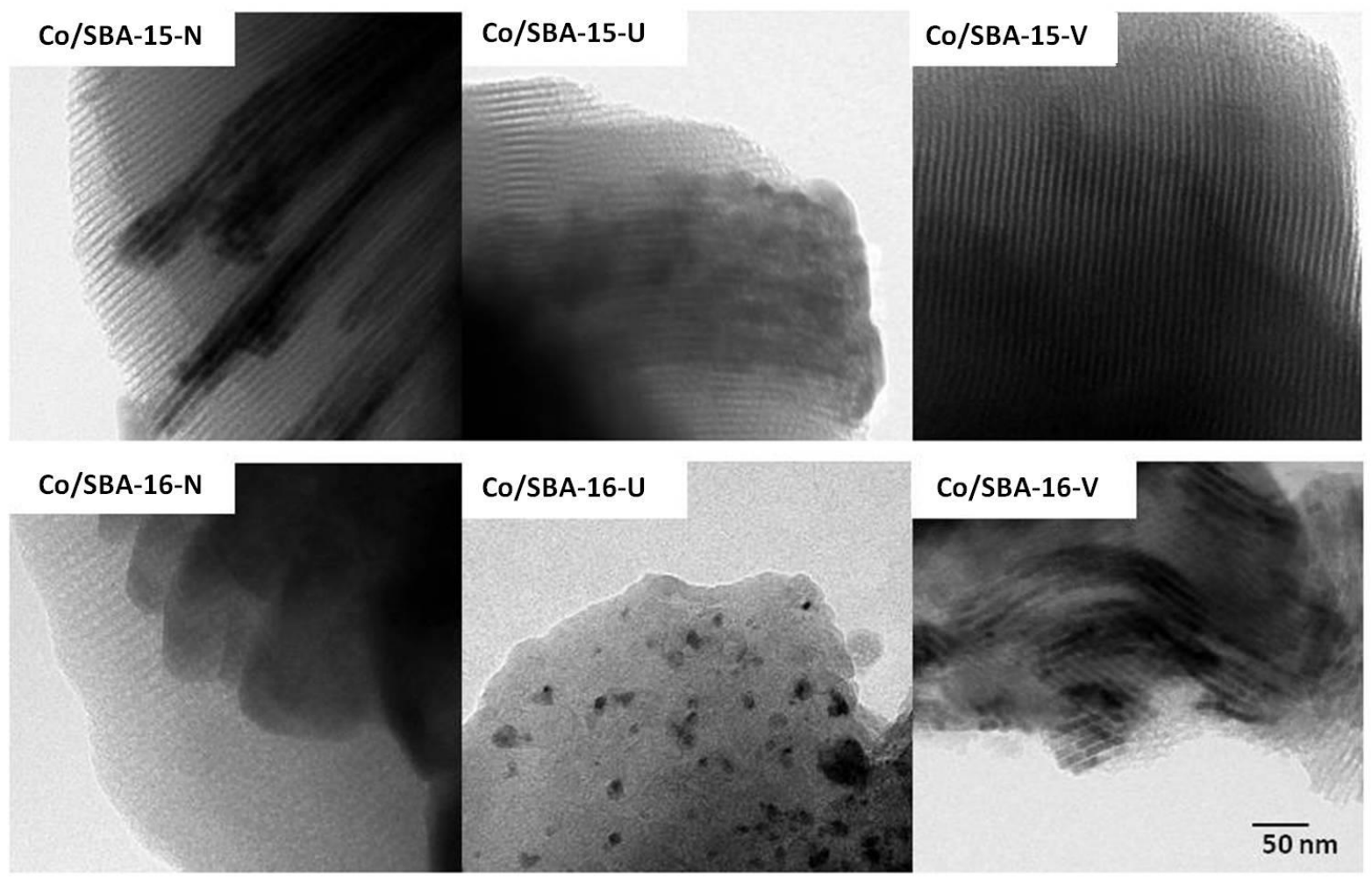

Fig. 4. TEM images ofdifferent catalysts.

The amounts of cobalt distribution based on the EDX measurement are shown in Table 2. It reveals how much the cobalt oxide can distribute over the silica surface. It was found that both post-impregnation treatments increased the metal distribution similar to TEM results and previous reports $[4,5]$. The amounts of cobalt oxide on the support surface decreased in the order of ultrasound treatment $>$ vacuum treatment $>$ non-treatment. The TEM results can be confirmed by EDX measurement (Table 2), where the amounts of cobalt species near surface are detected. For both SBA-15 and SBA-16 supports, the higher amounts of cobalt species were found for ultrasound treatment (rich on the outside) with compared to those for the vacuum treatment. As far as we know, the metal crystallite size is inversely proportional to the distribution [25]. The ultrasound and vacuum treatments decreased the metal crystallite size bringing about an increase in the metal distribution on the supports. However, these results could not explain the total dispersion properties of the catalysts because dispersion properties are considered based on the metal form (not metal oxide forms). In fact, the different support types are a significant factor to raise the metal distribution [26]. The SBA-15 exhibited higher surface area and larger pore size and pore volume than the SBA-16, but the SBA-16 served better metal distribution than the SBA-15 due to its unique properties. 
Table 2. Cobalt oxides distribution results from EDX analysisand their crystallite sizes.

\begin{tabular}{ccc}
\hline Sample & $\mathbf{W} \mathbf{t} \%$ of cobalt on support ${ }^{\mathbf{a}}$ & ${\text { Cobalt oxide crystallite size }(\mathbf{n m})^{\mathbf{b}}}$ \\
\hline Co/SBA-15-N & 28.18 & 17.6 \\
Co/SBA-15-U & 45.90 & 20.2 \\
Co/SBA-15-V & 38.48 & 22.6 \\
Co/SBA-16-N & 49.16 & 14.1 \\
Co/SBA-16-U & 75.81 & 19.1 \\
Co/SBA-16-V & 49.36 & 16.0 \\
\hline
\end{tabular}

${ }^{a}$ Measured by the EDX analysis

${ }^{\mathrm{b}}$ Calculated from the XRD measurement based on Scherrer Equation

Temperature programmed reduction is one of the most powerful techniques to identify the reduction behaviors of catalysts regarding to the metal dispersion and metal-support interaction. The TPR profiles of the SBA-15 and SBA-16 catalysts are given in Fig. 5 and Fig. 6, respectively. A typical reduction of silicasupported cobalt catalyst is commonly occurred in temperature range of $200-600{ }^{\circ} \mathrm{C}[2,23,27,28]$. The reduction is accomplished in two steps. The first reduction occurs around $220-320^{\circ} \mathrm{C}$, which can be assigned to the reduction of $\mathrm{Co}_{3} \mathrm{O}_{4}$ to $\mathrm{CoO}$, and the second step occurs around $320-500{ }^{\circ} \mathrm{C}$, which can be assigned to the reduction of $\mathrm{CaO}$ to $\mathrm{Co}$. Cobalt silicate can be formed when the temperature is raised above $500{ }^{\circ} \mathrm{C}$ depending on the support type [23]. Among the SBA-15 supported cobalt catalysts, the Co/SBA-15-N has two reduction peaks around $280-420^{\circ} \mathrm{C}$ and $480-520^{\circ} \mathrm{C}$. However, the Co/SBA-15-U and the Co/SBA-15$\mathrm{V}$ exhibited only single broad reduction peak due to the smaller cobalt particles and uniform crystallite size of cobalt dispersed on the SBA-15. Furthermore, the reduction temperature of the SBA-15 was shifted to lower temperature after ultrasound and vacuum treatments. This is probably because ultrasound and vacuum treatments after incipient wetness impregnation can decrease the metal-support interaction, so the catalysts are easily reduced [29].

For the SBA-16 supported cobalt catalysts, the Co/SBA-16-N has two reduction peaks about $300-420^{\circ} \mathrm{C}$ and $480-550^{\circ} \mathrm{C}$ as same as the SBA-15-N. Moreover, the TPR profile of the Co/SBA-16-U is similar to that of the Co/SBA-16-N. The Co/SBA-16-U still displayed high metal-support interaction that contrasts of the Co/SBA-15-U. Nevertheless, when the vacuum treatment was applied to the SBA-16, the reduction temperature was shifted to lower temperature and the peak around $500{ }^{\circ} \mathrm{C}$ was disappeared. This result suggests that the Co/SBA-16-V exhibited reduction at lower temperature than the Co/SBA-16-N and the $\mathrm{Co} / \mathrm{SBA}-16-\mathrm{Usince}$ the vacuum treatment may reduce the interaction between cobalt and theSBA-16 supports. However, the small reduction peak at high temperature approximately $650{ }^{\circ} \mathrm{C}$ was observed in case of $\mathrm{Co} / \mathrm{SBA}-16-\mathrm{V}$. This peak can be assigned to the reduction of non-stoichiometric cobalt-silicate, which is more difficult to reduce than $\mathrm{Co}_{3} \mathrm{O}_{4}$ species [30]. The vacuum treatment seems to be the suitable way to diminish metal-support interaction and to increase the metal distribution for the Co/SBA-15 and the Co/SBA-16. For better understanding, Scheme 1 is illustrated based on the TPR measurement. 


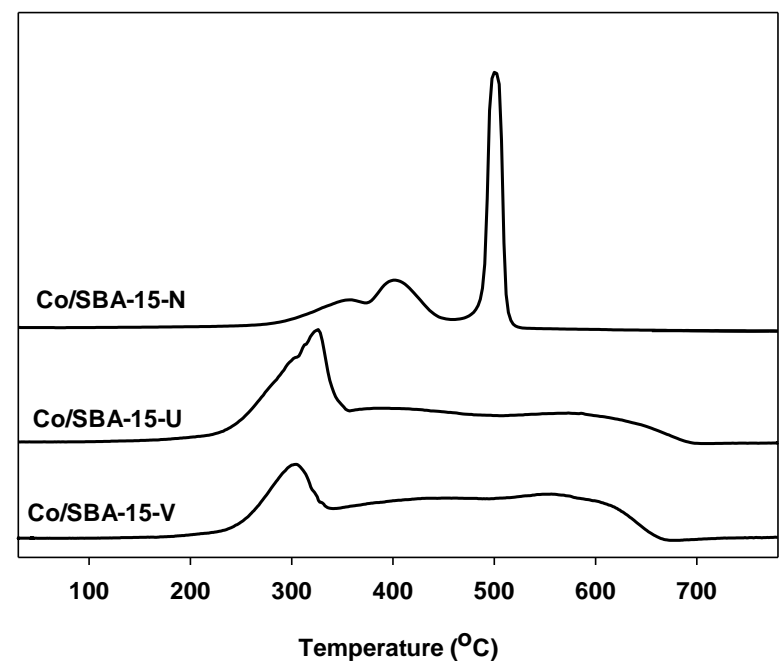

Fig. 5. TPR profiles of different post-impregnation treatments of the Co/SBA-15 catalyst.

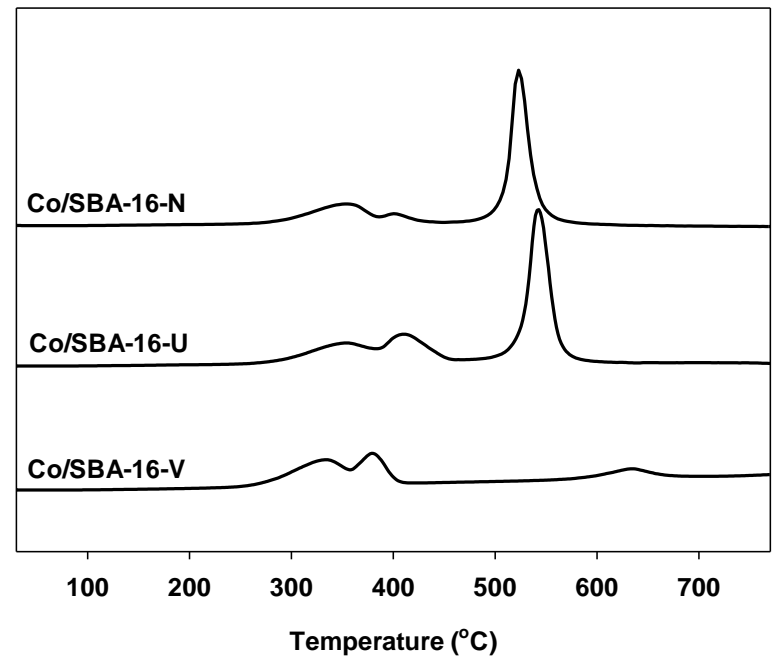

Fig. 6. TPR profiles of different post-impregnation treatments ofthe Co/SBA-16 catalyst. 
Co/SBA-15

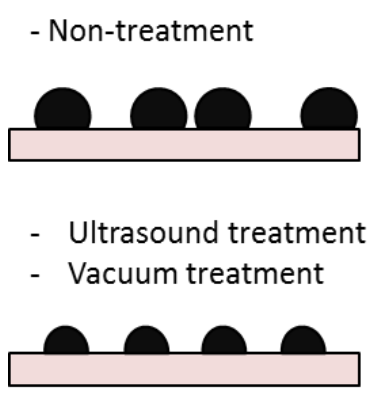

Co/SBA-16

- Non-treatment

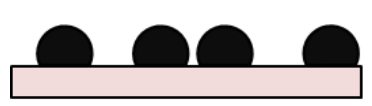

- Ultrasound treatment

- Vacuum treatment

\section{Reduction temperature}

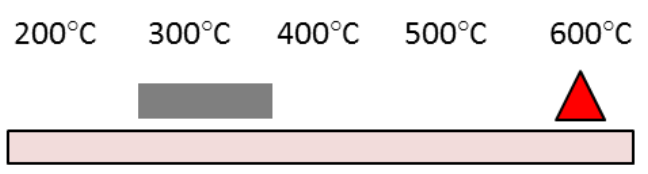

\section{Reduction}
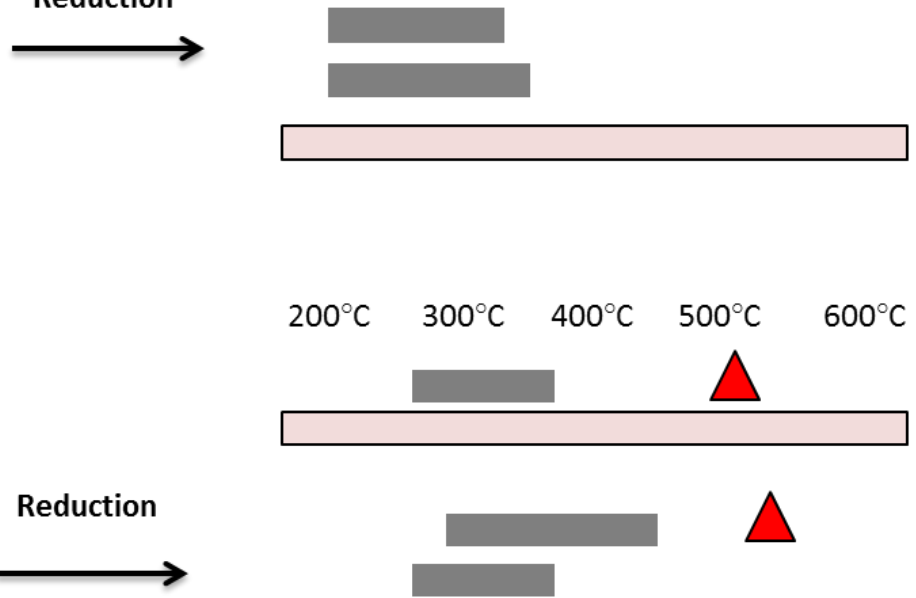

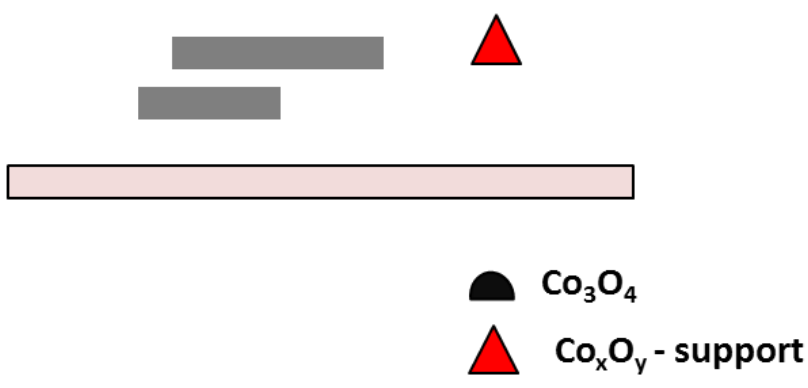

$\mathrm{Co}_{3} \mathrm{O}_{4} \rightarrow \mathrm{CoO} \rightarrow \mathrm{Co}^{\circ}$

Scheme 1. Conceptual model for reduction of the Co/SBA-15 and Co/SBA16 catalysts.

In order to determine whether or not cobalt silicate was formed after TPR measurement, the reduced Co/SBA-16-N catalyst was characterized by XRD. The XRD patterns obtained from the reduced Co/SBA16-N catalyst is given in Fig.7. The XRD pattern of the Co/SBA-16-N before reduction shows only the $\mathrm{Co}_{3} \mathrm{O}_{4}$ as mentioned before, whereas the XRD patterns of the $\mathrm{Co} / \mathrm{SBA}-16-\mathrm{N}$ after reduction presented cobalt metal in the fcc and hcp crystallographic forms [31]. However, no XRD peaks of the cobalt silicate were detected. It can suggest that either the cobalt silicate was not formed or the crystallite size of cobalt silicate was less than $3 \mathrm{~nm}$ and was the highly dispersed form. 


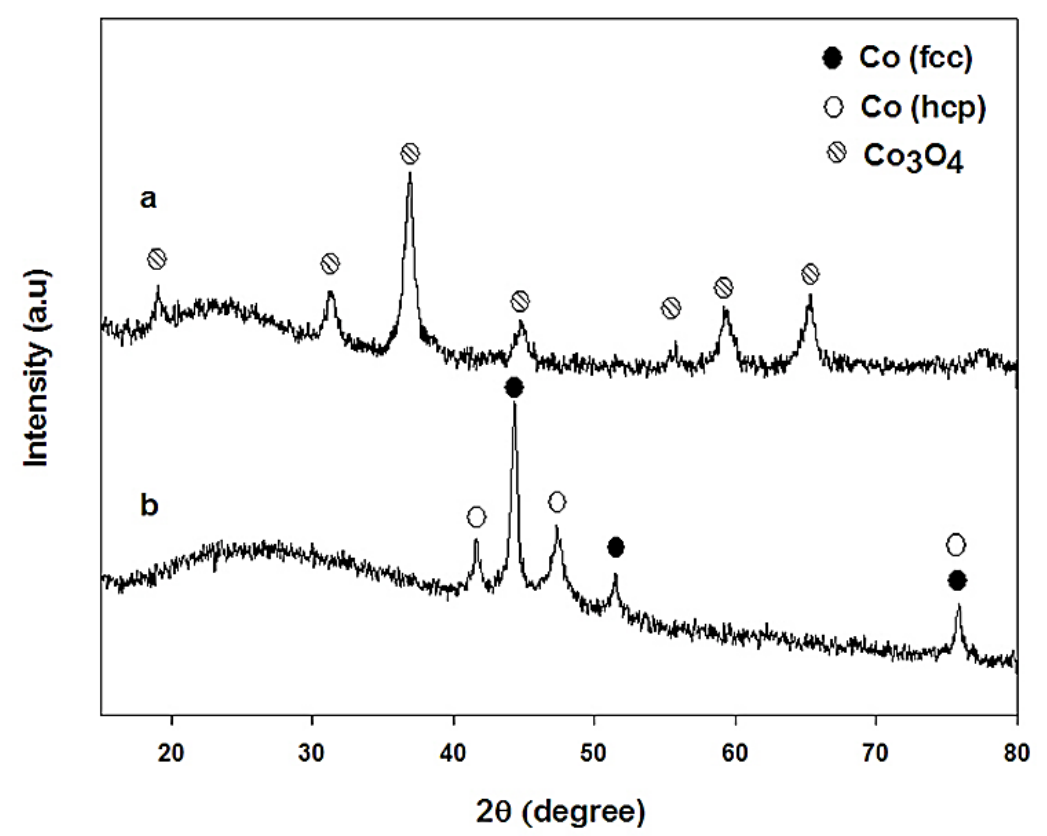

Fig. 7. XRD patterns of the Co/SBA-16-N catalyst: (a) before reduction (b) after reduction.

\subsection{Reaction Study}

The simple $\mathrm{CO}_{2}$ hydrogenation under methanation was used to investigate the catalytic properties. The $\mathrm{CO}_{2}$ conversion and activity are presented in Table 3. Products which mostly consist of $\mathrm{CH}_{4}$ and $\mathrm{CO}$, were collected at initial state $(10 \mathrm{~min}$ after reaction starting) and steady state $(6 \mathrm{~h}$ after reaction starting). The catalysts after the vacuum treatment exhibited the highest activity for both the Co/SBA-15and the Co/SBA16 catalysts. For the ultrasound treatment, the Co/SBA-15-U was twice the activity of the Co/SBA-15-N, and the activity of the Co/SBA-16-U was slightly higher than that of the Co/SBA-16-N. The catalytic properties are obviously related to the TPR results. The strong metal-support interaction led to poor activity. This may be because the difficulty in catalyst reduction causes the presence of many cobalt inactive species. It has been suggested in the previous report that the $\mathrm{Co}^{2+}$ is an inactive species performed highly interaction between the metal and the support, which is either $\mathrm{CoSiO}_{4}$ or cobalt silicate [32]. Therefore, the lower metalsupport interaction catalysts have higher catalytic activity since they have higher active cobalt species. Based on this study, the $\mathrm{CO}_{2}$ conversion increases in the order of vacuum treatment >ultrasound treatment $>$ nontreatment.

Table 3. $\mathrm{CO}_{2}$ hydrogenation results of the $\mathrm{Co} / \mathrm{SBA}-15$ and $\mathrm{Co} / \mathrm{SBA}-16$ catalysts.

\begin{tabular}{ccc}
\hline Catalyst & $\begin{array}{c}\text { Conversion } \\
\mathbf{( \% )}\end{array}$ & $\begin{array}{c}\text { Activity } \\
\left(\times \mathbf{1 0}^{\mathbf{2}} \mathbf{~}_{\left.\mathbf{C H 2} \mathbf{2} \cdot \mathbf{g}_{\mathbf{c a t}} \mathbf{- 1}^{\mathbf{2}} \mathbf{- 1}\right)}\right.\end{array}$ \\
\hline Co/SBA-15-N & 3.9 & 2.49 \\
Co/SBA-15-U & 8.1 & 5.22 \\
Co/SBA-15-V & 9.6 & 6.59 \\
Co/SBA-16-N & 3.0 & 1.89 \\
Co/SBA-16-U & 3.6 & 2.32 \\
Co/SBA-16-V & 14.4 & 8.99 \\
\hline
\end{tabular}

Reaction condition: $220^{\circ} \mathrm{C}, 1 \mathrm{~atm}, \mathrm{H}_{2} / \mathrm{CO}_{2}=10: 1$. The conversion and activity based on the amount of methane formation. Conversion and activity were determined after running for $6 \mathrm{~b}$.

\section{Conclusions}

The vacuum and ultrasound treatment after impregnation were employed for the Co/SBA-15 and Co/SBA16 catalysts. Both treatments can enhance the cobalt dispersion of the cobalt metal on the SBA-15. However, 
only the vacuum treatment was suitable for improving the cobalt dispersion on the Co/SBA-16. It was suggested that the vacuum and ultrasound treatments probably affect reducing the crystallite size of cobalt oxide species and a decrease in the metal-support interaction causing more cobalt atoms reduction. The catalytic activity of the Co/SBA-15 and the Co/SBA-16 for $\mathrm{CO}_{2}$ hydrogenation were increased after the vacuum and ultrasound treatments. The $\mathrm{Co} / \mathrm{SBA}-16-\mathrm{V}$ has the highest activity and $\mathrm{CO}_{2}$ conversion.

\section{Acknowledgement}

The authors thank the Thailand Research Fund (IRG5780014) and Grant for International Research Integration: Chula Research Scholar, Ratchadaphiseksompot Endowment Fund for financial support of this project.

\section{References}

[1] T. Das and G. Deo, "Synthesis, characterization and in-situ DRIFTS during the $\mathrm{CO}_{2}$ hydrogenation reaction over supported cobalt catalysts," J. Mol. Catal. A: Chem., vol. 350, no. 1-2, pp. 75-82, 2011.

[2] S. Alayoglu, S. K. Beaumont, F. Zheng, V. V. Pushkarev, H. Zheng, V. Iablokov, Z. Liu, J. Guo, N. Kruse, and G. A. Somorjai, " $\mathrm{CO}_{2}$ hydrogenation studies on $\mathrm{Co}$ and CoPtbimetallic nanoparticles under reaction conditions using TEM, XPSand NEXAFS,”Top. Catal., vol. 54, pp. 778-785, 2011.

[3] N. Srisawad, W. Chaitree, O. Mekasuwandumrong, A. Shotipruk, B. Jongsomjit, and J. Panpranot, " $\mathrm{CO}_{2}$ hydrogenation over $\mathrm{Co} / \mathrm{Al}_{2} \mathrm{O}_{3}$ catalysts prepared via a solid-state reaction of fine gibbsite and cobalt precursors," ReacKinetMech Cat., vol. 107, no. 1, pp. 179-188, 2012.

[4] C. Pirola, C. L. Bianchi, A. D. Michele, P. Diodati, D. Boffito, and V. Ragaini, "Ultrasound and microwave assisted synthesis of high loading Fe-supported Fischer Tropsch catalysts, Ultrasonic Sonochemistry," Ultrason Sonochem., vol. 17, no. 3, pp. 610-616, 2010.

[5] X. Zhou, Q. Chen, Y. Tao, and H. Weng, "Effect of vacuum impregnation on the performance of $\mathrm{Co} / \mathrm{SiO}_{2}$ Fischer-Tropsch catalyst," J. Nat. Gas Chem., vol. 20, no. 4, pp. 350-355, 2011.

[6] C. T. Kresge, M. E. Leonowicz, W. J. Roth, J. C. Vartuli, and J. S. Beck, "Ordered mesoporous molecular sieves synthesized by a liquid-crystal template mechanism," Nature, vol. 359, pp. 710-712, 1992.

[7] J. S. Beck, J. C. Vartuli, W. J. Roth, M. E. Leonowicz, C. T. Kresge, K. D. Schmitt, C. T. W. Chu, D. H. Olson, and E. W. Sheppard, "A new family of mesoporous molecular sieves prepared with liquid crystal templates,"J. Am. Chem. Soc., vol. 114, no. 27, pp. 10834-10843, 1992.

[8] Q. Cai and J. Li, "Catalytic properties of the Ru promoted Co/SBA-15 catalysts for Fischer-Tropsch synthesis," Catal. Commun., vol. 9, no. 10, pp. 2003-2006, 2008.

[9] B. K. Vu, E. W. Shin, I. Y. Ahn, J.-M. Ha, D. J. Suh, W.-I. Kim, H.-L. Koh, Y. G. Choi, and S.-B. Lee, "The effect of tin-support interaction on catalytic stability over Pt-Sn/xAl-SBA-15 catalysts for propane dehydrogenation," Catal Lett., vol. 142, no. 7, pp. 838-844, 2012.

[10] J. Panpranot, S. Kaewgun, and P. Praserthdam, "Metal-support interaction in mesoporous silica supported cobalt Fischer-Tropsch catalysts," Catal Lett., vol. 85, no. 2, pp. 299-304, 2005.

[11] J.Santamaría-González, J. Mérida-Robles, M.Alcántara-Rodríguez, P.Maireles-Torres, E. RodríguezCastellón, and A. Jiménez-López. "Catalytic behaviour of chromium supported mesoporous MCM-41 silica in the oxidative dehydrogenation of propane," Catal Lett., vol. 64, no. 2-4, pp. 209-214, 2000.

[12] S. Lestari, P. Mäki-Arvela, K. Eränen, J. Beltramini, G. Q. M. Lu, and D. Y. Murzin, "Diesellikehydrocarbons from catalytic deoxygenation of stearic acid over supported Pdnanoparticles on SBA15 catalysts," Catal Lett., vol. 134, pp. 250-257, 2010.

[13] Y.J. Han, G. D. Stucky, and A. Butler, "Mesoporous silicate sequestration and release of proteins," J. Am. Chem. Soc., vol. 121, no. 42, pp. 9897-9898, 1999.

[14] A. M. B. Furtado, D. Barpaga, L. A. Mitchell, Y. Wang, J. B. Decoste, G. W. Peterson, and M. D. Levan, "Organoalkoxysilane-grafted silica composites for acidic and basic gas adsorption," Langmuir, vol. 28, pp. 17450-17456, 2012.

[15] P. Yang, G. Wirnsberger, H. C. Huang, S. R. Cordero, M. D. Mcgehee, B. Scott, T. Deng, G. M. Whitesides, B. F. Chmelka, S. K. Buratto, and G. D. Stucky, "Mirrorless lasing from mesostructured waveguides patterned by soft lithography," Science, vol. 121, no. 42, pp. 9897-9898, 1999. 
[16] O. A. Anunziata, A. R. Beltramone, M. L. Martínez, and L. L. Belon, "Synthesis and characterization of SBA-3, SBA-15, and SBA-1 nanostructured catalytic materials," J. Colloid Interface Sci., vol. 315, no. 1, pp. 184-190, 2007.

[17] D. Zhao, Q. Huo, J. Feng, B. F. Chmelka, and G. D. Stucky, "Triblock copolymer syntheses of mesoporous silica with periodic 50 to 300 angstrom pores," J. Am. Chem. Soc., vol. 279, no. 5350, pp. 548-552, 1998.

[18] A. Katiyar, S. Yadav, P. G. Smirniotis, and N. G. Pinto, "Synthesis of ordered large pore SBA-15 spherical particles for adsorption of biomolecules," J. Chromatogr., vol. 1122, no. 1-2, pp. 13-20, 2006.

[19] D. Zhao, J. Sun, Q. Li, and G. D. Stucky, "Morphological control of highly ordered mesoporous silica SBA-15," Chem. Mater., vol. 12, No. 2, pp. 275-279, 2000.

[20] Q. Lu, Z. Wang, J. Li, P. Wang, and X. Ye, "Structure and photoluminescent properties of ZnOencapsulated in mesoporous silica SBA-15 fabricated by two-solvent strategy," Nanoscale Res Lett., vol. 4, pp. 646-654, 2009.

[21] H. Sun, Q. Tang, Y, Du, X. Liu, Y. Chen, and Y. Yang, "Mesostructured SBA-16 with excellent hydrothermal, thermal and mechanical stabilities: Modified synthesis and its catalytic application," $J$. Colloid Interface Sci., vol. 333, pp. 317-323, 2009.

[22] A. E. B. Cruz, J. A. M. Banda, H. Mendoza, C. E. Ramos-Galvan, M. A. M. Melo, and D. Esquivel, "Pt and Ni supported catalysts on SBA-15 and SBA-16 for the synthesis of biodiesel," Catal. Today.,vol. 166, no. 1, pp. 111-115, 2011.

[23] J. Janlamool, P. Praserthdam, and B. Jongsomjit, "Ti-Si composite oxide-supported cobalt catalysts for $\mathrm{CO}_{2}$ hydrogenation," J. Nat. Gas Chem., vol. 20, no. 5, pp. 558-564, 2011.

[24] S. Rojanapipatkul, J. G. Goodwin, Jr., P. Praserthdam, and B. Jongsomjit, "Effect of cobalt precursors on properties of $\mathrm{Co} / \mathrm{CoAl}_{2} \mathrm{O}_{4}$ catalysts Synthesized by solvothermal method," Engineering Journal, vol. 16, no. 4, pp. 5-13, 2012.

[25] L. Shi, Y. Jin, C. Xing, C. Zeng, T. Kawabata, K. Imai, K. Matsuda, Y. Tan, and N. Tsubaki, "Studies on surface impregnation combustion method to prepare supported $\mathrm{Co} / \mathrm{SiO}_{2}$ catalysts and its application for Fischer-Tropsch synthesis," Appl. Catal., A., vol. 435-436, pp. 217-224, 2012.

[26] C. Liu, J. Li, Y. Zhang, S. Chen, J. Zhu, and K. Liew, "Fischer-Tropsch synthesis over cobalt catalysts supported on nanostructured alumina with various morphologies," J. Mol. Catal. A: Chem., vol. 363-364, pp. 335-342, 2012.

[27] B. Jongsomjit, C. Sakdamnuson, J. G. Goodwin, and P. Prasertdam, "Co-support compound formation in titania-supported cobalt catalysts," Catal Lett., vol. 94, pp. 209-215, 2004.

[28] S. H. Kang, J. H. Ryu, J. H. Kim, I. H. Jang, A. R. Kim, G. Y. Han, J. W. Bae, and K. S. Ha, "Role of ZSM5 distribution on $\mathrm{Co} / \mathrm{SiO}_{2}$ Fischer-Tropsch catalyst for the production of $\mathrm{C}_{5}$ - $\mathrm{C}_{22}$ hydrocarbons," Energy Fuels., vol. 26, no. 10, pp. 6061-6069, 2012.

[29] J. Panpranot, N. Taochaiyaphum, B. Jongsomjit, and P. Praserthdam, "Differences in characteristics and catalytic properties of Co catalysts supported on micron- and nano-sized zirconia," Catal. Commun., vol. 7, no. 3, pp. 192-197, 2006.

[30] S. Rojanapipatkul and B. Jongsomjit, "Synthesis of cobalt on cobalt-aluminate via solvothermal method and its catalytic properties for carbon monoxide hydrogenation," Catal. Commun., vol. 10, pp. 232-236, 2008.

[31] W. Raróg-Pilecka, E. Miskiewicz, L. Kepinski, Z. Kaszkur, K. Kielar, and Z. Kowalczyk, "Carbonsupported cobalt catalyst for ammonia synthesis: Effect of preparation procedure," J.Catal., vol. 237, no. 1, pp. 207-210, 2006.

[32] A. Martínez, C. López, F. Márquez, and I. Díaz, "Fischer-Tropsch synthesis of hydrocarbons over mesoporous Co/SBA-15 catalysts: The influence of metal loading, cobalt precursor, and promoters," $J$. Catal., vol. 220, pp. 486-499, 2003. 